\title{
Organizational Factors of Career Management Employed IN THE TRANSITION ECONOMY
}

\begin{abstract}
:
The aim of this research was to determine which organizational factors have an impact on the realization of individual employee career plans. The sample was of a quotient, random selection of the respondent, of the size of 60 examinees $(n=60)$. It was formed from 20 large organizations from all over Croatia. The survey was conducted by direct survey. The regression analysis method was applied. The regression equation of organizational factors that affects the career development of employees is calculated and determined.
\end{abstract}

\section{Keywords:}

Employee careers; organizational factors

\section{Author's data:}

${ }^{1}$ Effectus, High School of finance and law, Zagreb, J.F. Kennedy square 2, e-mail: gutic.sanja@gmail.com

International Journal - VALLIS AUREA • Volume 5 • Number 1 • Croatia, June 2019 UDK 005.966-057.16; 001 10.2507/JJVA.5.1.4.58

of the six independent variables included, it was established that the most impacted on the career plan of the employees is the analysis and enrichment of the work, followed by psychological monitoring. The lowest coefficient of regression has been shown by career workshops and career charts. 


\section{Introduction}

In Human Resources Management, the Career management segment today is one of the key points. The realization of individual career plans employees is not only focused on the personal aspects, interests and contents of each employee, but also requires organizational support. Without organizational support, it is not realistic to realize a planned career. Employees successfully achieving their career plans achieve a higher degree of job satisfaction, greater productivity, creativity and innovation, loyalty to the organization, more responsible for doing jobs, avoiding better stress at work, etc. It is therefore an interest of all organizations that within the human resources management system potentials are applied in the best way to the management of employees' careers.

So far, a lot of works have been published, which outlined the methods, and the ways in which management seeks to help employees achieve the greatest satisfaction in achieving their careers. It is constantly emphasized and emphasizes that the role and support of the organization is irreplaceable in that. One of the fundamental characteristics of this is that these contributions are mainly contributed by the results generated in the developed human capital markets. By doing so, it reduces their applicative dimension in transition economies.

It is not unknown, and it is unexplored that organizations have a significant influence on their employees' careers. What is still largely unknown, and thus unexplored, are all the tools available to managers for successful career management.
This paper seeks to highlight organizational content and factors that can have a positive impact on the realization of individual career plans of employees in organizations in transition economies. It is believed that the research results that are being presented will provide a creative incentive for human resources management in these organizations to give greater attention to the careers of employees and direct their activities in this direction. One of the perhaps basic issues that will be encountered during the research is that the concept itself, and thus the model of human resources management in the transitional economy, is underdeveloped, researched and therefore reduced efficiently.

\section{Career success}

Career development and career management are measured by success. What is implicit in itself is: what is success in your career? There exist in the theory and practice of career management different opinions about it [2]. Career success is first and foremost individually colored and it is not possible to talk about the unique criteria and benchmarks that would be worth for each individual career. To evaluate career success, it is possible to use several criteria [12]:

a) Inner feelings related to employee satisfaction and the perception of this satisfaction,

b] The employee's life balance and achievement and the balance that consists of the balance between his work obligations and his nonwork obligations, 
c) The level of achievement of the realization of the life goals of the employees through the work and the organizations in which they are moving, d) The level of fulfillment and the efforts made regarding the realization of the established career development plan, the correction of the plan,

e) Autonomy in work and freedom of independent decision-making in the work process, f) The character of the working environment and the degree of employee identification with the organization and the working group,

g) Opportunities for selecting jobs and work tasks that are in line with the available knowledge and skills that the employee possesses,

h) Rank and status of employees in the working group and organization

Despite the developed career metrics and career achievements, some of these categories are still very difficult to quantify and objectively measure. Four approaches to looking at career performance [7]:

1. Individual approach,

2. Structural approach,

3. Behavioral approach,

4. Contemporary approach.

Individual approach comes from the theory of human capital. This approach simplifies the focus of career tracking metrics observed through individuals within the organization. They invest most in career development in their education, training, gaining experience and expect that they will be adequately rewarded based on their efforts and investments. According to this approach, career success is directly proportional to the quality of human capital that the individual brings to the labor market [6].

The structural approach is based on the assumption that there are a number of objective, different structural features that present limitations to the individual in the development of his career [8]. The size of the organization or its activity, or the organizational structure, are one of the structural factors. Larger organizations, for example, unlike smaller, have more structured and advanced organizational levels and opportunities and allow their employees to give more opportunities and efforts to advance in this organizational structure and thus in their career. In addition to the stated structural features, the structural approaches often include the frequency of employee advancement and the quality of the system of promotion of human resources in organizations [8].

A behavioral approach implies that employees have full control over their choice and career development. By doing so, they can assess their positions, roles and chances in organizations in the direction of their career development. The basic emphasis of this approach is that employees should permanently take proactive roles in developing their own career. This role can be realized using different interpersonal and intrapersonal strategies such as: self-initiation, identification, imitation etc. [2]. The main limitation in this approach is the existence of a perfect labor market and its functioning [11]. Within this perfect market, individuals can realize their career and measure success in their career. 
Contemporary career approaches are based on a cumulative outcomes in career development resulting from a long period of individual behavior. There are three approaches to the modern approach: the concept of an unlimited or boundless career, the concept of a protean career and the concept of an intelligent career [3].

\section{Organizations factors in career employees' management}

Human career is realized solely within organizational systems and differs from organization to organization. Organizations determine employee profiles, job content, job performance regimes, goals to be achieved, skills and skills that employees need to have successfully accomplished their tasks.

Seligman comes to the knowledge that people are advancing in their careers when they are able to develop positive emotions and emotional relationships, then positive psychosocial interactions in their working group, and a positive engagement in the organization [12]. He argues that due to the absence of these three components, there is a shortage of career development. The emphasis in this approach is mainly on the aspects of an individual employee, and not on aspects and content of an organization in supporting the development of each member's career. Ryan and Deci, present the research results that link the career development with the autonomy of the employees, their competencies during the work, and the connection of the work operations and the information they need to perform the job successfully [11]. They point to the need and more importantly try to promote the concept of intrinsic motivation of employees as significant support in career development. Although this approach has a shift towards Seligman's standpoint, a number of other factors that determine the success of employee careers, with which organizations can influence it, remain unclear. Valey brings the results of extensive psychological observations and research and points out that they need an effective career [16]: self-awareness; selfconfidence, cognitive knowledge, interpersonal competence; skills in achieving identity, communication skills; skills in running teams and teams. Though the great role and significance of these, as well as other numerous psychological determinants in career achievement, is not a real career success, just focus on them.

Perhaps one of the most important contributions to the identification of organizational factors in the realization of the career of employees is brought by Arthur and Rousseau. They claim to be [1]:

a) Self-employment tools for employment. Include: career planning workshops, selfmanaging career workshops, retirement retirement workshops, computer software and its implications in career management.

b) Assessment of organizational human potential. Includes career promotion, psychological monitoring, assessment centers, interviews, job analysis.

c) The internal labor market, which includes: career manuals, career charts, resource center, information support.

d) Individual employment counseling involving: managers, senior career advisors, 
human resource center staff, specialized external consultants.

e) Business analysis systems, including informal testing, job vacancy advertising, job auditing, rotation staffing, internal staffing systems.

f) Development programs that include: enrichment and design of jobs, job changes, inhouse training, external seminars and workshops, training costs reimbursement, training of career management supervisors, dual career programs, mentoring system, employee orientation.

Although this is a well-structured presentation, it is not realistic to consider that there are not many other organizational factors that can affect the realization of the career of employees.

Based on this systematization of organizational factors that assist in the realization of the career of employees, the following six factors are empirically investigated in the observed organizations:

1. Career workshops (Rpk), [15]

2. Career promotion (Pro], [6]

3. Psychological tracking [PSi], [8]

4. Analysis and enrichment of jobs (Apo), [10]

5. Career rankings [Ska], [13]

6. Revision and staffing rotation (Rev), [17]

\section{Methodology}

\section{Target}

The basic and sole objective of the research is to identify which organizational factors and to what extent they have an impact on the realization of individual employee care plans.

\section{Hypothesis}

The following basic hypothesis is defined in accordance with the set goal:

Ho - Successful realization of individual employee career plans depends on multiple organizational factors.

\section{Sample}

The sample was quotient, random selection of the respondent. The sample size was $60(n=60)$. It was formed from 20 large organizations from across Croatia, random selection. Only those organizations that have confirmed that they have a well established and developed Human resources management center are involved.

The sample did not include respondents with less than 10 years of work experience, as well as subjects older than 60 years of age. Also, no respondents who previously stated that they did not make a clear and understandable career plan or did not remember the elements of that plan were involved.

It is assumed that inclusion of less than ten years of work experience will not vield reliable results because they may not objectively offer valid answers to their career performance (career in the initial stage) and compare the same with the career plan [10]. No respondents older than 60 are involved because it is questionable how much they would be interested in participating in this survey cdrop in interest, retirement preparation, end of career) [10]. 


\section{Respondents}

The respondents were employees in various, large organizations from all over croatia. 50\% of respondents were men and $50 \%$ women, with $50 \%$ of middle class employees and $50 \%$ of high class employees.

\section{Test instruments}

The satisfaction of the satisfaction with the career accomplished was based on the questionnaire on satisfaction with the career realized [14]. The questionnaire was used in its entirety in an unaltered original form. Levels of satisfaction: completely dissatisfied [1], satisfied [2], completely satisfied [3].

Dependent variables were offered to respondents at five levels: it did not affect my career (1); very little has affected (2); influenced my career [3], greatly influenced my career (4), most influenced my career [5].

\section{Variables}

The independent variable (Y) is the realization of the career plan of employees, and the dependent variables are:

\section{Career workshops [Rpk],}

2. Careers promotion (Pro],

3. Psychological tracking [Psi],

4. Business analysis and enrichment (Apo),

5. Career rankings (Ska),

6. Revision and staffing rotation (Rev),

Other possible variables as systematically exposed to Arthur and Rosseau could not be included since they were not in career management in the observed organizations.

\section{Interviewing}

The survey was conducted by a direct survey during September-December 2018. There was a completely anonymous character about which respondents were notified before the start of the test. Surveys were conducted by interviewers prepared for this task.

\section{Methods}

The regression analysis method according to the equation was applied:

$$
\mathrm{Y}=\beta_{0}+\beta_{1} x_{1}+\beta_{2} x_{2}+\varepsilon
$$

or shown in the model of this research:

$$
\begin{gathered}
\mathrm{Y}= \\
\beta_{0}+\beta_{1} R p k+\beta_{2} \operatorname{Pr} 0+\beta_{3} P_{s i}+\beta_{4}{ }_{A p o}+\beta_{5} S k a+\beta_{6} \operatorname{Re} v+\varepsilon
\end{gathered}
$$

Coefficients of regression were estimated by the least squares method [5]:

$$
\mathrm{RSK}=\sum \varepsilon_{1}^{2}=\sum\left(Y_{1}-\hat{Y}_{1}\right)^{2}
$$

The F-test for determining the determination coefficient (R) and thet-test for the significance of the determinants were used [9]:

$$
{ }_{N-k} \approx \frac{\beta_{1}-0}{S_{\beta j}}
$$

Variation autocorrelation (DW) was performed using the Durbin-Watson test [4]:

$$
\mathbf{D W}=\frac{\frac{\sum_{t=2}^{T}\left(\varepsilon_{t}-\varepsilon_{t-1}\right)^{2}}{\sum_{t=1}^{T} \varepsilon_{t}^{2}}}{2}
$$


Limitations

Observed organizations have largely had developed forms of human resources management, but within them are still underdeveloped forms and management content of the career of employees. There was also a considerable difficulty in the nonhomogeneous structure of career management model of employees within organizations [6].

Certainly, for a larger study, it would be good to form larger size samples, preferably with multiple layers of choice. However, given the resource potential and the objective of this research, it was not possible.
Data processing

For the statistical analysis of the data collected, the SPSS for Windows software version (version 20.0, SPSS Inc., Chicago, Illinois, USA] was used.

\section{The results}

The following regression equation of organizational factors influencing the career development of employees has been calculated and determined:

$$
\begin{aligned}
& \mathrm{Y}=\text { 7,425 - 0, } 1508 \mathrm{Rpk}+\text { 0, } 3511 \text { Pro+ 0, } 5279 \text { Psi- 0, } 6025 \text { Apo+ 0, } 2714 \text { Ska } \\
& + \\
& \text { 0, 4921 Rev } \\
& \mathrm{t} \quad 2,52 \quad 4,03 \quad 1,84 \quad 7,49 \\
& \mathrm{R}^{2}=0,86 \quad \mathrm{~F}=8249 \quad \mathrm{DW}=1,87
\end{aligned}
$$

From the equation there is an approximate and possible conclusion that the organizational factors involved in the realization of the career plan employed by the perceived flow of the respondents have the most influence on the analysis and enrichment of the jobs and then the psychological monitoring. The lowest coefficient of regression shows career workshops and career rankings.

Employees, in fact, experience that their career performance is most affected by the various activities that management takes in the field of monitoring work, analysis, and adding new content to their jobs. Also, various forms of psychological assistance, advice and suggestions during the job are considered to have a significant influence on the course and career achievement.
It is not a satisfying role for the existence and functioning of a career workshop that can have a negative impact on career achievement in the long run, as employees do not acquire the necessary personal knowledge through the training sessions within the workshops and the interaction of knowledge about managing their own career. Thus, in a certain sense, the role and significance of individual efforts of every employee to care for their career is undermined, which can negatively affect the success of a career. Likewise, the low-ranking career rankings point to the possible conclusion that observed organizations have not sufficiently developed their organizational structure within which there are no clearly visible layers of hierarchical upsets emploved during their career or are not clearly visible and available to employees. 
A relatively high determination coefficient suggests that $86 \%$ variance of the dependent variables is interpreted with the sixindependent variables included. Thus, only 14\% remained untroubled, which would probably be further reduced by the possibility of inclusion of any of the possible organizational variables that Arthur and Rousseau systematically exhibit [1].

The I values, shown at each regression coefficient, indicate that all independent variables in the study are statistically significant at the $5 \%$ significance level.

The high $F$ value of the regression equation indicates that the determination coefficient is significant. Thus, all six coefficients of regression involved are significantly different from zero. F values do not indicate the possible multicollinarity among the examined variables.

Given the calculated value of the Durbin-Watson test, it is concluded that there is no autocorrelation of the first rank among the observed variables.

\section{Discussion}

What is the wisdom and reality of this research?

Since no positive autocorrelation was observed among the observed variables, it was not necessary to determine the established regression model with additional variables. If that was the opposite, it is questionable how much it could be. Namely, the practical and additional variables could not be generated in the observed organizations. Adequate transformations of existing, involved variables would in that case be not only demanding but rather uncertain. It remains debatable how many other, exogenous, noninvolved variables that make up the personal characteristics of each of the respondents (employees outside the organization] affect the overall satisfaction of the respondents with a career. But the answer to that question was not the focus of this research.

It is also questionable how many other, exogenous, non-included variables that make up the personal characteristics of each of the respondents (employees outside the organization) affect the overall satisfaction of the respondents with the career. But the answer to that question was not the focus of this research.

The regression equation presented in this paper is not realistically understood statically, but dynamically. The level of satisfaction of respondents by developing their career is not definitive, but forms and develops during their remaining career. Thus, established organizational factors are changing over time, both quantitatively and qualitatively. Therefore the regression equation could be complemented as:

$\Delta \mathrm{Y}=7,425-0,1508 \Delta \mathrm{Rpk}+$ 0, $3511 \Delta$ Pro+ 0, $5279 \Delta \mathrm{Psi}-0,6025 \Delta$ Apo+ $0,2714 \Delta \mathrm{Ska}+0,4921 \Delta \mathrm{Rev}$

The regression coefficients in this equation are not constant in the duration of the career of employees and should therefore be understood and interpreted. Possible errors in the regression equation partly derive from the release of other independent variables which, due to situational factors, are not included in the regression model. One of the approaches in reducing or eliminating this possible mistake is through covariant analysis whereby by introducing several apparent variables into a regression model it will be eliminated.

\section{Conclusion}

The basic and sole objective of this research was to identify which organizational factors and to what extent they have an impact on the realization of individual employee care plans. of the six independent variables included, it was established that the performance of the career plan employed by the perceived flows of the respondents most influenced the analysis and enrichment of the work, and then the psychological 
monitoring. The lowest coefficient of regression has been shown by career workshops and career charts. Not a satisfactory part of the existence and functioning of career workshops and career charters.

This suggests a possible conclusion that observed organizations have not sufficiently developed their organizational structure within which there are no clearly visible strata of hierarchical ascents employed during their careers. The inadequate elaboration and application of numerous instruments with which organizations can efficiently manage the career of their employees is typical of the vast majority of organizations in the transition economy. Since it has been confirmed that all six variables included have an impact on the career of employees, it can be accepted that the objective of this research has been successfully implemented. This is a hypothesis related to the purpose of the research.

\section{References}

[1] Arthur, M.B. \& Rousseau, D.M. (1996). The boundaryless career, oxford University Press, ISBN 0-19510014-X, oxford

[2] Baruch, Y. [2006]. Career development in organizations and beyond: Balancing traditional and contemporary viewpoints. Human Resource Management Review, No 16, September, 2006, pp. 125-138, ISSN 1053-4822

[3] Briscoe, J.P., Hall, D.I. \& Frantschy DeMuth, R.L. (2006). Protean and boundaryless careers: An empirical exploration, Journal of Vocational Behavior, No 69, June, 2006, pp. 30-48, ISSN 0001-8791

[4] Durbin, J. \& Watson, G.S. (1951). Testing for serial correlation in last squares regression II, Biometrica, No 38 (1-2), February, 1951, pp. 159-179, ISSN 14643510

[5] Freedman, D.A.(2009). Statistical Models: Theory and Practice: Cambridge University Press, ISBN 978-0-52111243-7, Cambridge, USA
[6] Gattiker, U.E. \& Larwood, L. (1986). Subjective career success: A study of managers and support personnel, Journal of Business and Psychology, No2, October, 1986, pp. 78-94, ISSN 1573-353-X

[7] Hall, D.I. [2002]. Protean careers in and out of organizations, Sage Publications, ISBN 13:9780761915478, Thousand Oaks, CA

[8] Mohsin, A., Lengler, J. \& Kumar, B. [2013]. Exploring the antecedents of intentions to leave the job: The case of Iuxury hotel staff. International Journal of Hospitality Management, № 35, May, 2002, pp. 48-58, ISSN 0278-4319

[9] Panchenko D. (2006). Statistics for Applications, Section 14, Simple Linear Regression. Massachusetts Institute of Technology, ISBN 16-963-047293305-2, Massachusetts

[10] Reidy, S., Ma, C [2016]. How do we create robust internal labor market so that employees can move freely into new roles? Cornell University, ILR School, ISBN 0-11-610428, New York

[11] Ryan, R.M. \& Deci, E. L. (2000). Self determination theory and the facilitation of intrinsic motivation, social development, and well.being, Americam Psychology Journal, No 55, Apriil, 2000, pp. 68-79, ISSN 0003-066-X

[12] Seligman, M. (2011]. Flourish: A new understanding of happines, well-being and how to achieve them. Nichols Brealey Publishing, ISBN 10-9781439190760, Boston

[13] Swamy, D.R., Nanjundeswarasawamy, I.S. \& Tashmi, S. (2015) Quality of work life: Scale development and validation, International Journal of Caring Sciences, Vol.8, November, 2015, pp. 281-304, ISSN 1792037-X

[14] Swarnalatha, I. [2013]. Questionnaire on an empirical analysis of work-life balance, Journal of Organizational Behavior, № 23, June, 2013, pp. 731-748, ISSN 1099-1379

[15] Trofimov, A. \& Bondar, Y. (2014). Theoretical relationship between career mobility and 
organizational commitment, Fundamental and applied researches in practice and leading scientific schools, Taras Shevchenko National University, Kyiv, Ukraine, No 6, December, 2014, pp. 37-61, ISSN 2313-7525

[16] Valey, R.S. (2007). Mental skills training in sport handbook og sport psychology, Tannenbaum, G. \& Eklund, R.C., ISBN 8-33084622, New York

[17] Zin, M. (2003]. The relation between job rotation practices and employee career development among production workers in Japanese companies in Malaysia, Mediterranean Journal of Social Sciences, № 6 (11), March, 2003, pp. 124-143, ISSN 2039-2117 